\title{
Spiritual Support During COVID-19 in England: A Scoping Study of Online Sources
}

\author{
Irena Papadopoulos ${ }^{1}$ D $\cdot$ Runa Lazzarino ${ }^{1} \cdot$ Steve Wright $^{1} \cdot$ Poppy Ellis Logan $^{1}$. \\ Christina Koulouglioti ${ }^{1,2}$
}

Accepted: 1 April 2021 / Published online: 19 April 2021

(c) The Author(s), under exclusive licence to Springer Science+Business Media, LLC, part of Springer Nature 2021, corrected publication 2021

\begin{abstract}
Spiritual support is a key element of holistic care, and better healthcare professionals training and stronger strategic guidelines become urgent in light of health disasters and emergencies, such as the COVID-19 pandemic. To this end, the aim of this study was to explore spiritual support provision within mass and social media and the websites of spiritual leaders, institutions and NHS chaplaincy units during COVID-19 in England, between March and May 2020. A scoping review design informed by Levac and colleagues' five-staged framework was adopted, and adapted with a multi-strategy search to scope the different domains of online sources. Results revealed that spiritual support for dying patients, their families, health care staff, spiritual leaders and chaplains, had to be drastically reduced, both in quality and quantity, as well as being provided via different technological devices or domestic symbolic actions. No mention was found of a central strategy for the provision of spiritual support. This study points to the importance of developing centralized strategies to prepare healthcare systems and professionals in relation to spiritual support provision, both routinely and during health disasters and emergencies. Further research will have to explore innovative practices, in particular the role of digital technologies, in spiritual support provision.
\end{abstract}

Keywords COVID-19 $\cdot$ Hospitalised patients $\cdot$ Spirituality $\cdot$ Bedside spiritual support · England

Irena Papadopoulos

R.Papadopoulos@mdx.ac.uk

1 Research Centre for Transcultural Studies in Health, Department of Mental Health and Social Work, Faculty of Health, Social Care and Education, Middlesex University, The Burroughs, London NW4 4BT, UK

2 Research and Innovation Department, Western Sussex Hospitals NHS Foundation Trust, Chichester, UK 


\section{Introduction}

The World Health Organization declared the outbreak of COVID-19 a pandemic on the 11 March 2020, and less than 2 weeks later, the UK Prime Minister announced the implementation of several restrictions advertised by the slogan "Stay home, Protect the NHS, Save Lives". The infection and death rates increased rapidly, and during the early weeks of the COVID-19, the UK government and the National Health Service (NHS) were not fully aware on how to best approach its treatment and prevention and were unprepared for this health emergency (The Guardian, 2020). The UK is one of the top twenty countries affected by COVID-19 worldwide, scoring fifth for number of cases and deaths; this implies that the burden of COVID-19 has been very high, with-at time of writing-over 61,200 deaths and many more sick people spending days, or weeks, of suffering and/or being ventilated artificially in intensive care before most of them dying (Johns Hopkins Coronavirus Resource Center, 2020). Both anecdotal accounts and evidence from available studies around spiritual care during COVID-19 emphasized the lack of spiritual support (Ferrell et al., 2020; Ribeiro et al., 2020; Roman et al., 2020), as well as the lack of preparedness within the healthcare systems, which were found not to be equipped to enable staff and spiritual service providers to respond to those in need.

Spirituality is an integral part of being human (Papadopoulos, 1999), and spiritual care is a key element of holistic care pivoting around compassion and cultural competence (Papadopoulos, 2018). Research around the benefits of spiritual support is advancing and new evidence corroborates the fact that patients with advanced illness, and those dying, find considerable comfort from prayer, or just the presence of someone who can hold their hand and be with them as they take their last breaths (Ho et al., 2018; Papadopoulos \& Copp, 2005). A recent literature review (Ho et al., 2018) identified several benefits associated with meeting the spiritual needs of patients in intensive care units, such as perceived improvement in care quality, enhanced patient satisfaction, and a better perception of care among family members. Similar results are reported in a recent systematic review of spiritual support in terminal illness (Chen et al., 2018), and indicate that spiritual care can improve care quality and patients' wellbeing, as also found in a study focusing on patients' perspective (Ebenau et al., 2020). Echoing these findings, a third review in palliative care in Europe showed that the effects of spiritual care are positive, particularly in terms of reducing patients' discomfort (Gijsberts et al., 2019).

Nurses have a historic role in supporting the spiritual well-being of patients (Royal College of Nursing, 2011), and, as a study with acute care nurses in New York City found (Gallison et al., 2013), addressing patients' spiritual needs is considered part of their role. However, the same study also reports that only nearly half of the sampled nurses declared to participate in spiritual practices due to several barriers, including lack of time, convictions around the privacy of spirituality, difficulties to provide it when beliefs were different from their own, and difficulties to separate it from proselytism (Gallison et al., 2013). These findings 
resonate with those of another study where nurses working in End of Life (EoL) were found to provide less spiritual care than they desired, reported inadequate training and that the idea that spiritual support was not lying within their professional role; these factors were also key predictors of reduced spiritual support (Balboni et al., 2014). Another study reviewing the literature around barriers to spiritual care for nurses in hospital settings, found that scarce clarity around the definition of spirituality, the dearth of training, time and guidelines for nurses' role were the main issues concerning the provision of holistic care that includes spiritual support (Rushton, 2014). Current outcomes of training in spiritual care appear promising (Dezorzi et al., 2019; Hu et al., 2019; Paal, 2015), and studies have discussed the importance of incorporating spiritual care into basic educational activities and models, in palliative care and beyond (Best et al., 2020; Piscitello \& Martin, 2020).

Meeting nurses training needs and developing strategic guidelines in the realm of spiritual care becomes urgent in light of disasters and emergencies being on the rise worldwide (Chapman \& Arbon, 2008; International Federation of Red Cross $\&$ Red Crescent Societies, 2018). International institutes urge governments to strengthen strategies for disaster reduction with concrete management plans (ISDR, 2007; WHO, 2019), which include disaster preparedness training of all healthcare professionals (Achora \& Kamanyire, 2016; Schultz et al., 2012). Nurses represent an indispensable workforce during disasters (Magnaye et al., 2011), and preparedness for adequate response is crucial (International Council of Nurses \& World Health Organization, 2011). In mass casualty situations, the demand for spiritual support grows exponentially with the death toll, and nurses bear one of the greatest burdens of care, including that of patients' spiritual well-being (McBrien, 2010). Nonetheless, research and strategies around emergency and disaster preparedness in relation to spiritual support appear scarce. In England, the NHS programme of work known as Emergency Preparedness, Resilience and Response (EPRR) (NHS England, 2017) appears to be lacking plans to prepare nurses and their managers in relation to spiritual support, including during pandemic influenzas and other infectious diseases (Sellwood, 2017).

\section{Aims of the Study}

The primary aim of this study was to explore and report how and what spiritual support was covered by mass and social media, and by the websites of spiritual leaders/institutions and those of the UK NHS during the early peak of COVID-19 in England. A secondary aim of this study was to comment on the existence of national strategies for dealing with major hazards and disasters and, in the case of their absence, to highlight their need (Papadopoulos et al., 2020). There is no universal definition of spirituality, due to its subjective nature and focus on the 'self' (Sinclair et al., 2006; Walton, 2012). Accordingly, spiritual care is associated with several interventions, including healing presence, patient- and meaning-centredness, and the establishment of a spiritually rich environment (Ghorbani et al., 2020). In the present scoping study, spirituality is defined by four universal dimensions and some individual meanings (see Box 1). Furthermore, 
Box 1 Dimensions/meaning and examples of spiritual support

\begin{tabular}{|c|c|}
\hline Dimensions of spiritual support & Examples of spiritual support \\
\hline \multicolumn{2}{|l|}{ Some universal dimensions } \\
\hline Search for existential meaning & $\begin{array}{l}\text { Sit with the patient and actively listen to them talking. Per- } \\
\text { haps hold their hand or make them comfortable }\end{array}$ \\
\hline $\begin{array}{l}\text { Search for a power other than the self, } \\
\text { which may not necessarily be called } \\
\text { "God" }\end{array}$ & $\begin{array}{l}\text { Encourage them to talk about life and death. Ask them if } \\
\text { there is anything they want you to do especially relating to } \\
\text { their family }\end{array}$ \\
\hline Reference to the soul of the person & $\begin{array}{l}\text { Being open to their concepts of spirit and soul can help } \\
\text { relieve suffering }\end{array}$ \\
\hline Links to the holy, sacred, divine, religious & $\begin{array}{l}\text { Ask them if they wish to see a religious or spiritual care } \\
\text { specialist. Ask if they wish you to read a prayer or, if you } \\
\text { can, to read their favourite part from their holy book }\end{array}$ \\
\hline \multicolumn{2}{|l|}{ Some specific/individual meanings } \\
\hline $\begin{array}{l}\text { Feelings, inspirations, reverence, awe, } \\
\text { meaning and purpose of life and a } \\
\text { search for the infinite }\end{array}$ & $\begin{array}{l}\text { Encourage the patient to talk about all these if they wish. Sit } \\
\text { next to the bed and actively listen. Try to act on any wishes } \\
\text { or requests they may have }\end{array}$ \\
\hline A journey towards inner peace & $\begin{array}{l}\text { Use meditation which will help a patient to find inner peace. } \\
\text { Ask them if they wish to see a religious/spiritual care } \\
\text { specialist }\end{array}$ \\
\hline A meaning to illness & $\begin{array}{l}\text { Illness can have therapeutic gains if the patient is helped to } \\
\text { explore the significance of their illness in their life }\end{array}$ \\
\hline Shared values & $\begin{array}{l}\text { Kindness, co-operation, caring, tolerance, and compassion } \\
\text { can help the patient to give meaning to his/her illness and } \\
\text { find inner peace }\end{array}$ \\
\hline
\end{tabular}

the term spiritual support is preferred, since it is broader than spiritual care, which is commonly used and investigated in nursing care (Ramezani et al., 2014; Royal College of Nursing, 2011). In the WHO ICD - 10/11-AM Spiritual Intervention Codings (WHO-SPICs), spiritual support is described as "the provision of a ministry of presence and emotional support to individuals or groups", and is only one component of spiritual care, along with assessment, counselling, guidance and education, ritual, and allied health interventions (Carey \& Cohen, 2015; Carey \& Gleeson, 2017; WHO, 2017). In this paper, we use the term spiritual support differently, as an integral component of culturally competent and compassionate care (Papdopoulos, 2018). In this sense, spiritual support entails a spiritual presence, comfort and other actions not only towards patients, but for their loved ones as well as for health workers. Spiritual support stems from an "understanding [of] the suffering of others and wanting to do something about it [and] takes into consideration the patients' and the carers' cultural backgrounds as well as the context in which care is given" (Papadopoulos, 2018, p. 2). This conception of spiritual support is intended to apply to all healthcare professionals, from nurses to medical clinicians, and is not restricted to the professional interventions of chaplains. 


\section{Methodology}

This scoping study is informed by the framework originally proposed by Arksey \& O'Malley (2005), and further developed by Levac and colleagues (2010) and Peters and colleagues (2020). According to this framework, the review has been organised into five stages [i.e. (1) identifying the research question; (2) identifying relevant sources; (3) sources selection; (4) charting the data; (5) collating, summarising and reporting the findings] and adapted to scope evidence different from academic and grey literature, i.e. online sources such as websites, and social media postings in Facebook and Twitter.

\section{Identifying the Research Questions}

The following research questions guided the scoping study: (a) To what extent has the provision of spiritual support for the COVID-19 hospitalised patients been covered by mass and social media and the websites of spiritual leaders/institutions and those of the NHS, in England, in the period between 20 March to 20 May?; (b) How has the provision of spiritual support for the COVID-19 hospitalised patients been represented within by mass and social media and the websites of spiritual leaders/institutions and those of the NHS, in England in the period between 20 March to 20 May?; (c) Has the COVID-19 pandemic affected how spiritual support is conceived, valued, and given within the NHS in England in the period between 20 March to 20 May?; (d) What are the lessons we can draw from the findings of this study?

\section{Identifying Sources}

This scoping review considered sources available online only, and searches were conducted on the World Wide Web (from now onwards 'Web'), on relevant organisations' websites, and on selected online mass and social media. The search strategy was articulated along four main domains and piloted for each of them. Pilot searches confirmed the general appropriateness and feasibility of the search strategy, and the only modification to the protocol that the research team agreed on, was the abandonment of the search term "support" because it appeared to be yielding too many irrelevant sources (sources not related to spirituality, but to other types of support, such as the provision of support in the community, for example, the delivery of food to vulnerable older adults).

Search strategy 1 . Search of the Web using the free text terms and sets of combinations always including "spiritual", "COVID-19", "patients", and "England", in combination with other terms such as compassion, spiritual leaders, chaplains, and hospitals. Examples of search terms combinations are provided in Box 2a. The pilot search with this strategy indicated that after 100 Google results using a specific set of terms data, saturation was reached. After scanning 500 Google results, using 
Box 2 Search terms per search strategy

(a) Search strategy 1-search terms and combinations using Boolean operators

Spiritual AND initiatives AND pandemic AND England

Spiritual AND covid19 AND England

Spiritual AND hospitalised patients AND England

Spiritual AND coronavirus AND England

Spiritual AND nurses AND England

Spiritual AND healthcarers AND England

Spiritual AND patients AND covid AND England

Spiritual AND chaplains AND England

Spiritual AND spiritual leaders AND England

Spiritual AND religious leaders AND England

Spiritual AND caring AND England

Spiritual AND NHS and covid AND England

Spiritual AND dying AND covid AND England

Spiritual AND healing AND covid AND England

Spiritual AND hope AND covid AND England

(b) Search strategy 2-searched organisations

Royal College of Nursing

European Federation of Nurses Associations

Commonwealth Nurses and Midwives Federation

European Transcultural Nursing Association

International Council of Nursing

National Institute for Health and Care Excellence

Spiritual England

British Association for the Study of Spirituality

Centre for Spirituality

Health and Disability

Anglican Mission in England

Woking Muslim Mission

Hindu Forum of Britain

Jewish Care

Royal College of Nursing

(c) Search strategy 4

Hashtags (\#) used for Twitter search $\quad$ Twitter and Facebook accounts of key spiritual leaders searched

\#spiritual \#pandemic

\#spiritual \#chaplain

\#covid \#chaplain

\#hospitalchaplain

\#hospitalchaplains

\#spiritualcare

\#chaplaincy

\#coronavirus \#cv19 \#covid19
Bishop of London @BishopSarahM

London Diocese @dioceseoflondon

Church Times@ChurchTimes

Chief Rabbi Mirvis @ chiefrabbi

Marcus Walker @WalkerMarcus (A clergyman in the Church of England, Diocese of London)

Muslim council of Britain @ MuslimCouncil

Finsbury Park Mosque @FPMosque

The Church of England @ churchofenglandselected 
five different terms' combinations, no relevant pages were being generated and this search was concluded.

Search strategy 2. The websites of relevant institutes and organisations concerned with healthcare and spirituality were searched. These organisations were either established a priori, based on the knowledge of the research team, and involved international organisations which include UK/England as member (i.e. Box 2b); or they were identified via the previous Search strategy 1; or via snowball sampling.

Search strategy 3. Selected online TV news outlets (BBC News and ITV News) and online newspapers (The Sun, The Daily Mirror, The Guardian, and The Daily Telegraph) were searched using the Google search engine. The same key terms presented above, in Search Strategy 1, were used to explore these selected sources.

Search strategy 4. The following social media were searched: Facebook and Twitter. For the latter, a series of hashtags \# associated with above search terms (Search strategy 1) were used (see Box 2c). Specifically, Twitter and Facebook accounts of key spiritual leaders, such as the Church of England Archbishop, leaders of the Catholic Church and churches of other denominations and other religions were also identified and searched (see Box 2c). Inside these potential sources, a search of all of the posts published within the study time range was conducted, and these were filtered for each hashtag and search term.

All searches were conducted between June to August 2020, using Safari and Google search engines. To assist with managing the collation, screening, and extraction of data, searches were divided among the research team members in the following three domains: (1) search of the Web with Google and organisations websites; (2) online mass media; and (3) social media (Twitter and Facebook). All sources identified by searches for potential inclusion were downloaded in full-text onto Word files kept by each researcher. No special software was used for the management of the search results, and files were shared among the research team in a secured OneDrive cloud folder. Figure 1 summarises the selection of sources in accordance with PRISMA guidelines, and following the search strategies above delineated.

\section{Sources Selection}

Only sources dealing with spiritual support-as per working description used in this paper (see Box 1) —relating primarily to hospitalised COVID-19 patients, relatives and caregivers (including spiritual support providers) according to the following categories were included: (a) semantic field (terminology and synonyms); (b) as formalised in nursing and healthcare (spiritual care, palliative care and chaplaincy); (c) ideas and conceptions (common, lay understanding); (d) actions and initiatives (petitions, fund raising, awareness raising); (e) impact of COVID-19 onto spiritual support provision.

The source of information/stories could be about the patient, the nursing staff, the spiritual leaders, the families of patients, a journalist interviewing the above, a friend of the patient or family. No age or demographic restrictions were applied, apart from the context which was limited to England, and the source language which was English. Only material published online between 20 March and 20 


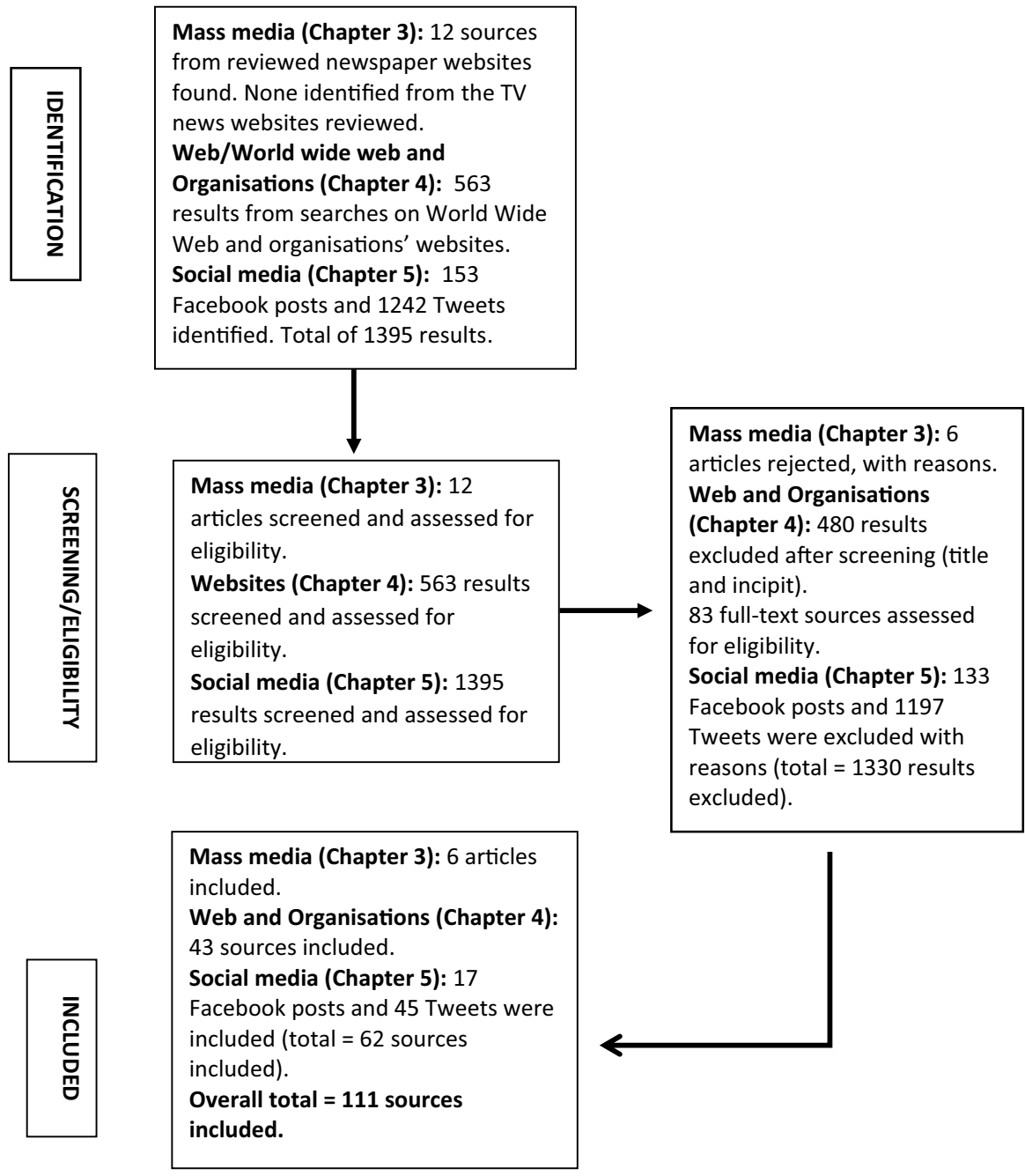

Fig. 1 PRISMA FLOW diagram illustrating sources search process

May 2020 were considered, because this period represented the peak of the pandemic in England, UK (first wave). However, in relation to sources in Search strategy 1 and 2, where the exact date of publication was not always available, the team decided to consider that sources from hospitals were falling within the study time range as well as some of the resources providing advice and resources, because there were some references to phenomena and events linked to the first two months of the pandemic in England, e.g. Easter, or high numbers of dying patients, or self-isolation and lockdown. If a source was slightly post-dated, but clearly referring to occurrences which happened within the study time range, it 
was included. Academic literature of all kind and sources not available online were excluded.

\section{Charting the Data}

Details and data from included sources were extracted using a standardised piloted data extraction form employed by each researcher in their own search domain. Information that was charted included two broad categories: (1) Evidence Source Details and Characteristics (bibliographic information with URL and date of access); (2) Details/Results extracted from source of evidence (context, target population, key findings that relate to the project's review questions-e.g. action/initiative described, link between COVID-19 and spiritual support, how spiritual support is described, other-on some occasion accompanied by direct quotes).

\section{Methodological Excellence and Accuracy}

According to Denzin and Lincoln (2017) qualitative researchers should be more concerned about methodological excellence and accuracy rather than validity; they should be concerned with transferability, rather than generalisability, and dependability, rather than reliability. The authors believe that this study met all these criteria in a number of ways. All procedures were carefully developed and discussed by the five members of the team, and were subsequently piloted and adjusted accordingly. This assured accuracy in the data collection, and dependability in the analysis and interpretation of the results. To increase accuracy and dependability, each researcher independently verified the work of at least one of their colleagues and the whole team had regular meetings to discuss all processes and result. The authors believe that the findings provide detailed evidence for transferability as the results will resonate with many nurses and other health professionals.

\section{Results}

Given the heterogeneity of sources and data in this review, results are presented separately for each of the three search domains. Findings are presented as follow: employing a narrative synthesis rich in direct quotes - for the online mass media domain - and using a descriptive synthesis for the domain of organizations' websites and of social media. Table 1 synthetises overall results by search domain, offering both key figures of the types of spiritual support actions/initiatives and of sources included per thematic categories, and key sub-themes. A link to the project report section per each thematic category is provided. 


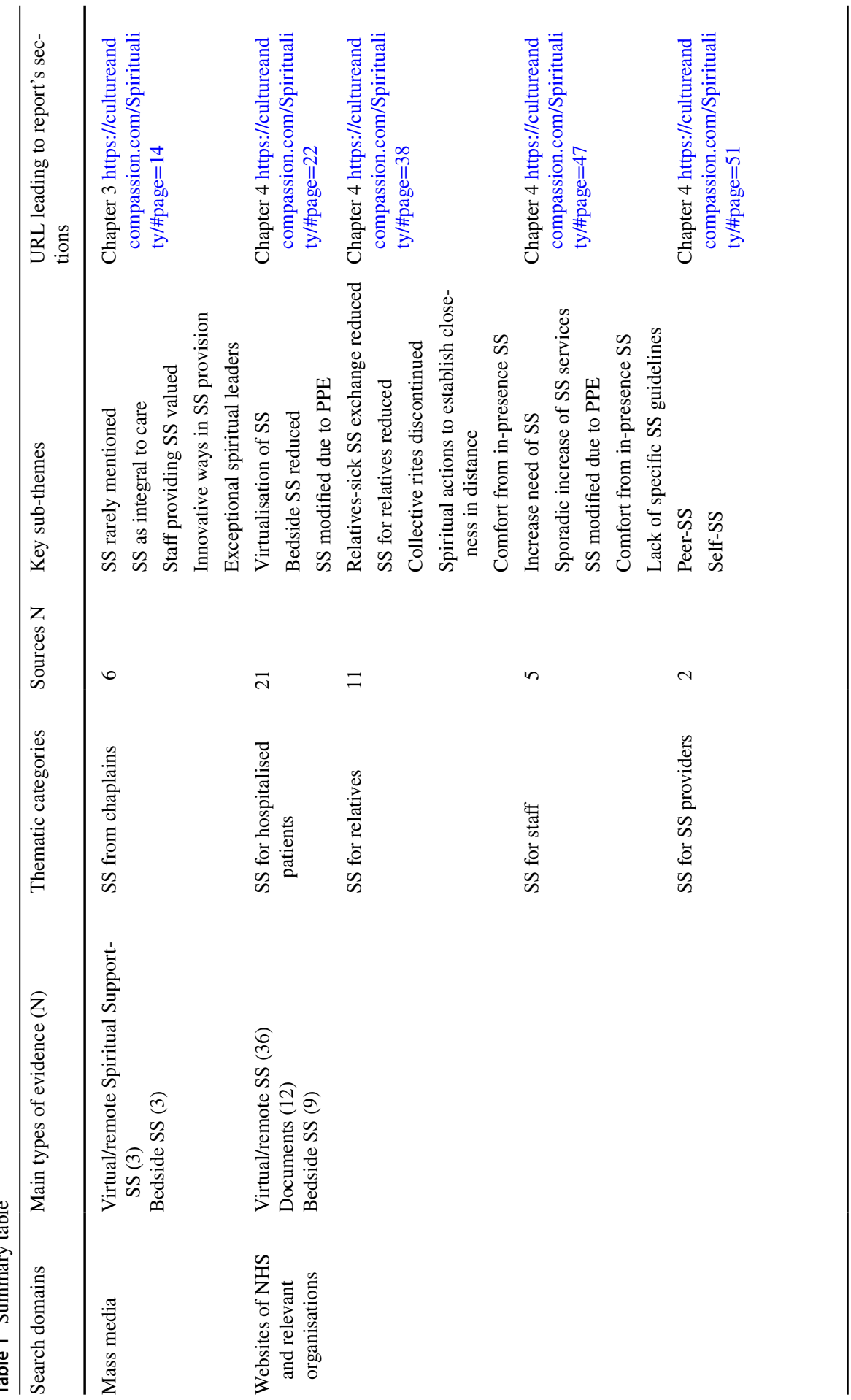




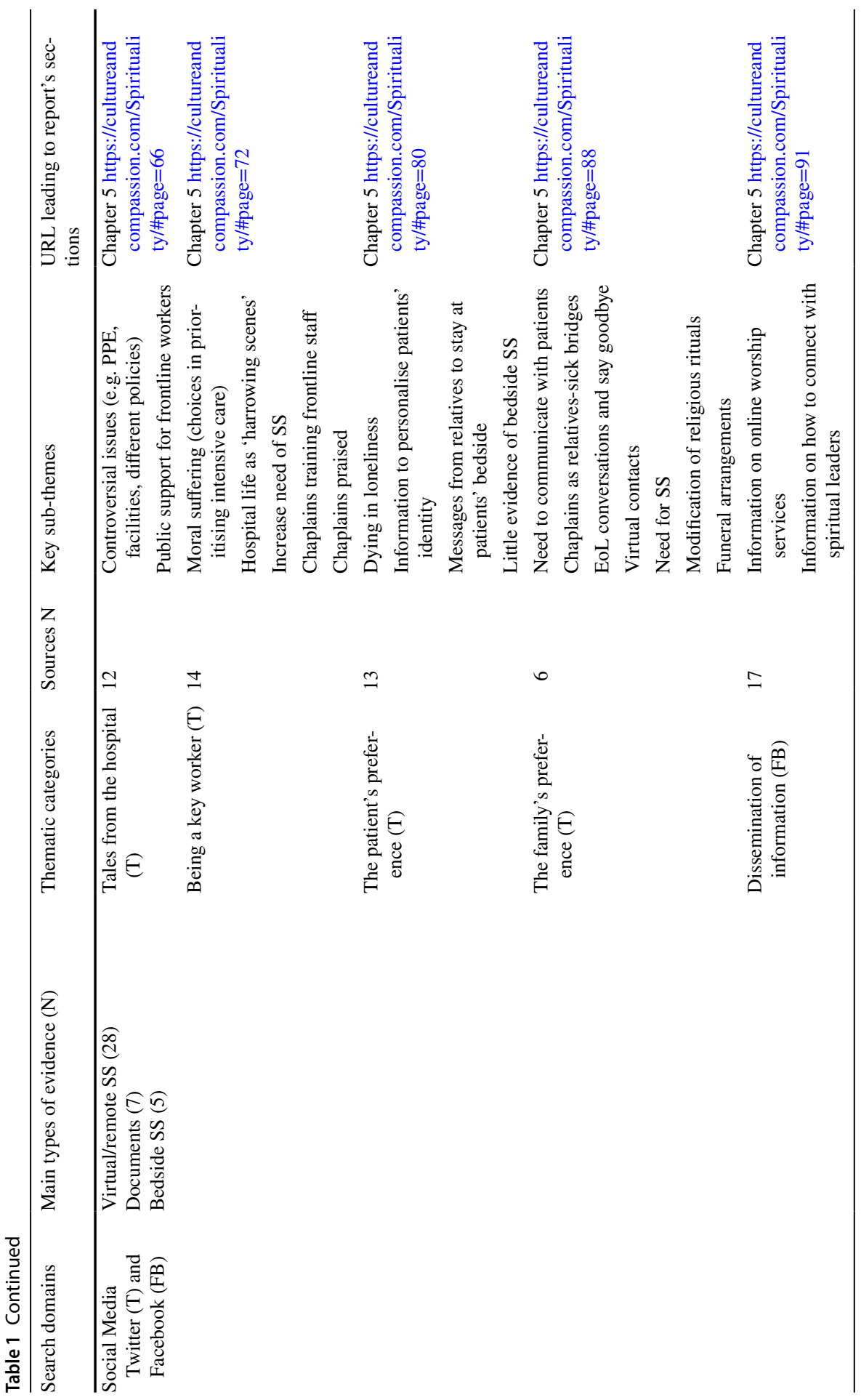




\section{Online Mass Media Domain}

In the selected mass media, the provision of spiritual support for hospitalised COVID-19 patients received little mention and no relevant stories were found in either of the TV news websites. The newspaper reporting represented spiritual support as an integral part of care for patients, staff, and relatives, and the efforts made by staff to provide such support under such extremely difficult circumstances were particularly valued (see Box 3a). Particular attention was given to innovative approaches that were adopted for providing spiritual support for patients being treated in isolation-essentially virtual spiritual support-and to some exceptional cases of spiritual leaders secretly acting as volunteer chaplains who were playing an active role in providing spiritual support, despite the risk (see Box 3b).

\section{Domain of Organizations' Websites}

The majority of sources consist of evidence of remote action, where spiritual support is offered over the phone, or via statements of support, or where strategies for support at distance are suggested which do not necessarily entail the use of technology, or sets of online resources for self-spiritual support-essentially prayers and links to videos; nine sources consist in testimonies of front-line spiritual support providers working in hospitals, hence being evidence of bedside spiritual support (see Table 1). Other sources consist of documents such as guidelines, protocols, and information from NHS hospitals or religious organisations. If we exclude hospitals and Trusts' chaplaincies $(n=19)$, sources coming from religious organisations, including interfaith coalitions $(n=14)$, outnumbered those from non-denominational bodies $(n=10)$. It is important to notice that one source could belong to more than one type of evidence, for example guidelines and informative communication could be found together with the remote action type. Evidence is described below following the four main categories in which sources have been grouped according to the main target population in receipt of spiritual support.

The main modification in the provision of spiritual support to patients has been its 'virtualisation', thanks to the use of technological devices. Secondly, where inperson bedside spiritual support could be offered, this had been reduced both in numbers - as often only emergency cases could be catered for-and in quality, due to the heavy PPE that the spiritual support providers or staff always had to wear. Spiritual support provision for relatives was affected both in terms of being unable to exchange support with their sick loved ones, and to receive it from chaplains and spiritual leaders. Congregational rituals had to be suspended, and relatives were in quarantine, therefore celebrations and commemorations had to occur virtually from home, and in solitude, including funerals and requested masses by name. Other sources offered strategies to relatives in order to establish invisible connections, such as lighting a candle, practicing mediations, listening to music, etc. When chaplains could be visited, or when they could visit the loved ones in hospital and act as 
Box 3 Key quotes from mass media search domain

(a) SS as integral to care and its provision highly valued

Chaplains were also supporting NHS staff dealing with the emotional challenges of the pandemic. The Rev Dr Chris Swift, director of chaplaincy and spirituality for the MHA care home charity, and a former head of chaplaincy services at Leeds teaching hospitals, said: "Due to the crisis, there are a lot of nursing staff now on the frontline who have limited experience of end-of-life care. [...] Chaplains are supporting them as they are learning, and dealing with their own emotional response. To be unable to save people who are dying in respiratory distress is a very disturbing experience." Harriet Sherwood, The Guardian, 04/04/2020

We can't physically be beside very ill people for the same reasons as relatives can't" said Simon Harrison, president of the College of Health Care Chaplains. "Much emotional end-of-life care is now being delivered by doctors and nurses. So we're supporting medics who find themselves needing to be mindful of the spiritual and emotional needs of patients". Harriet Sherwood, The Guardian, 04/04/20

"The main thing for us as chaplains is to be there as a bit of support. I was able to support his family who knew that their loved one had received those important prayers. You're there when the family can't be. [...] Recently, on behalf of the daughter of someone, I was able to say to the patient what his daughter had said, recall all her memories of them together and make it more personal so they're not just a number in a bed. It's about making that link between the human and the hospital and the patient. $[\ldots]$ The eyes of that patient, staring into mine, just looking for reassurances... after that I got into my car and cried because you can't help. I was so moved that someone who has had a wonderful life, was very much loved, but couldn't have any of his loved ones around that bedside. [Father Craig Fullard, on-call hospital chaplain at Nightingale NHS Hospital, Birmingham].” Gabriella Swerling, The Daily Telegraph, 20/04/2020

"We have staff on wards who have gone to the patient with a phone wrapped in plastic and enabled them to hear their loved ones speak," she said. "I think the rules vary from hospital to hospital regarding what is allowed on a ward. [...] Afterwards, people just come back to us [Soul Midwives] and say that it has made such a difference to be able to make a connection with their loved one when they can't see or touch them. It gives them a direct link which is so moving." Gabriella Swerling, The Telegraph, 20/04/2020

\section{(b) Innovative approaches to SS and exceptional spiritual leaders}

Some patients have, at least, been able to communicate with friends and family via video conferencing apps on tablets donated to the hospital. W. [infection prevention control worker] found this especially moving when her grandfather was admitted with Covid-19. [...] "He was able to tell my family he loved them and to sign goodbye via FaceTime before he died" she says. Jonny Weeks, The Guardian, 20/03/2020

[...] in order to help people feel less isolated, a new social trend, endorsed by the Royal College of Nursing, has emerged whereby final messages are being passed on to help grieving relatives and dying patients feel less isolated. [...] She [Felicity Warner, founder and CEO of Soul Midwives] said that while patients are not necessarily able to communicate while on ventilators, their relatives are recording soothing music and personal messages to play to them at their bedside. [... "We have staff on wards who have gone to the patient with a phone wrapped in plastic and enabled them to hear their loved ones speak [...] "Think of it as a chance to get beyond the machines, and high-tech equipment in the hospital and get straight to the heart of that person". Gabriella Swerling, The Telegraph, 20/04/2020

"I think what we're finding is all of the things that are important—-the physical presence, the touch, the being there and witnessing what's going on —are all much more limited," says Dr Jo Elverson, a consultant in palliative medicine, who helped compile the guide [for relatives supporting dying patients, by The Centre for 'The Art of Dying Well' at St Mary's University, London. [...] "We're having to almost look at what's really core about those things and how we can do it differently." Rebecca Pocklington, The Sun, 22/04/2020

"He [the Archbishop of Canterbury, Justin Welby] gets a lot of solace from doing it. Just being able to physically see people and pray with them during lockdown-it's what the clergy has been doing the length and breadth of the country. [...] There is some personal risk but he doesn't really think about that. He just thinks this is what Christians should be doing, helping others." Camilla Tominey, The Daily Telegraph, 12/05/2020 
live bridges between relatives and patients, this was described as a great source of comfort.

Healthcare staff have also been affected by the reduction in spiritual support provision due to the pandemic. Accordingly, an increase in the request of chaplaincy service on behalf of staff was noticed, and in a few $(n=4)$ structures new services were set up, or old ones intensified, such as a staff support line run by chaplains working from home; group reflection sessions; informal staff 'well-being hubs' around the hospital; and occasionally one-to-one support. In those few hospitals $(n=11)$ where chaplains and spiritual leaders could be present in person, results indicate that this was of comfort to staff. Frontline staff have been the first providers of spiritual support themselves, and while a few guidance documents in relation to the provision of spiritual support during this emergency were found $(n=7)$, they appear very generic and, in many ways, almost identical to common chaplaincy guidelines which are focused on preparation rather than actual doing. Results suggest that spiritual support among spiritual support providers has been either peersupport or self-help/self-care, with instances in the sources describing leaders crying on each other's shoulder, or strengthening their coping skills with a morning prayer and affirmation.

\section{Social Media Domain}

\section{Twitter}

Data were aggregated in four main categories, and for each of these, a short descriptive synthesis is provided. The first category has been named 'Tales from the Hospital'. While a large range of tweets connected with the hospital overall, there were also tweets regarding controversial issues, such as the provision of PPE $(n=2)$, differences between NHS Trusts around their policies to spiritual support $(n=3)$, or the inadequate hospital resources and facilities and the re-purposing of mosques to be used as hospitals. Several tweets referred to the public thinking about the great difficulty of those working in hospitals and praying for both patients and staff $(n=5)$.

The second category focused on being a key worker. Scenes of moral suffering, where workers were required to prioritise healthy bodies over those of more elderly or disabled patients, were described. Elsewhere, "harrowing scenes" is the phrasing used in place of a more vivid description of hospital life. As a result, there is a recognition on social media that doctors and nurses working on the front line were themselves in need of spiritual support from hospital chaplains, in order to provide adequate care to patients. Furthermore, chaplains were also required to give training on EoL care to those clinical staff going to the frontline for the first time- such as student nurses. Broadly, a large body of tweets were praising —or advocating for praising - the work of the hospital chaplains.

The third category is where there is a discussion about the patient and their preferences, with a widespread recognition of the loneliness that patients in hospital were facing $(n=3)$. Some chaplains commented about what it was like to support and reassure patients, who were dying without any friends or family beside them, 
with their eyes being the only part to be seen. In one Trust, patients' friends and relatives were encouraged to send in information and stories about the patients, which would be share with the doctors to ensure that each patient was "not just a number in bed". Similarly, another Trust promoted the "thinking of you" scheme, which encouraged friends and family members to send in messages for their loved ones, stating the ward, bed number and the surname of that patient. These details were printed and given to patients, and would not leave their side-due to risk of contamination - so that they could become a permanent reminder of the love and presence of their relatives.

Many tweets recognised the importance of the chaplain in enabling communication between the clinical team, patients and their family members. The importance of discussions around the EoL preferences and having the opportunity to say goodbye to a loved one was seen as essential for families to deal with grief. Some Trusts enabled patients to speak to their families, by wrapping phones in plastic coverings and holding them next to the patients' ear. There was also acknowledgment of the importance of providing spiritual support to the family members to help them cope with bereavement, or anxiety around their loved one's EoL care. Many people discussed concerns over patients and staff members not being able to attend to their normal religious practices. Some religions offered "plenary indulgence" to patients, and absolution to staff members who were caring for people with the virus. Chaplains sought to perform modified religious rituals for patients, such as anointing them using cotton bud tips. Where allowed to approach patients, chaplains sought to offer respite to families by being there to witness the patient's death and being able to tell families what happened in their loved one's final moments. Finally, there were a range of tweets regarding funeral arrangements and conditions, such as the preparation of the body, whether or not the body could be buried or cremated, and who was allowed to attend.

\section{Facebook}

All posts were aggregated under one main theme, dissemination of information, as sources pivot around the provision of online worship services. Different organisations and individuals shared the schedules and/or events related to virtual worship, mass, days of prayers, spiritual talks, videos, and podcasts. They also shared documents and resources related to the disposal of the dead, ways of connecting with their church, temple, mosque, synagogue or others in order to received provided services.

\section{Discussion}

During the first peak of the COVID-19 pandemic in England, the media reported that, due to safety regulations, many of the thousands of dying patients were deprived of the last act of compassion, in the absence of visitors, family members, or friends. Our results point to a general recognition that patients were often left alone and the restrictions in place created tough conditions for them, their families 
and the organisations. In line with the recent WHO interim guidance (WHO, 2020), religious leaders, including chaplains, were unable to perform regular services and provide the same bedside spiritual support as pre-pandemic (Byrne \& Nuzum, 2020; Cockell, 2020). The pandemic was considered as an extreme, unprecedented existential crisis, which caught health providers and the government unprepared in terms of a national strategy which had been well-rehearsed and could be initiated and adequately resourced. The pandemic also created new societal systems and conditions of living, working and behaving, including how individuals care for themselves and others, when death is imminent (Bland, 2020; Blustein \& Guarino, 2020).

A recent study exploring the treatment of lonely deaths among older people in Intensive Care Units (ICU), during COVID-19 and before, showed how dying alone lies out of social norms (Nelson-Becker \& Victor, 2020). Dying alone is usually constructed as a form of 'bad death' (Seale, 2004), unless it reflects the individual choice (Turner \& Caswell, 2020). Solitary deaths are seen as undesirable, and almost all cultures and societies have established collective rituals to ensure the smooth passage from the world of the living to that of the dead (van Gennep, 2019). Our searches have detected that when the presence of someone could be offered, people expressed both gratitude and a great sense of comfort, corroborating the importance of holistic care, in ICUs and EoL particularly.

While low media coverage can be explained with editorial priorities focussing upon the startling rise in the number of cases of COVID infections and deaths, the reduction of bedside provision speaks to the unpreparedness of the NHS to deal with the scale of the pandemic, including the provision of a key service, such as spiritual support, as others have lamented too, for example in the US (Wakam et al., 2020) and Iran (Heidari et al., 2020). This further suggests that while some chaplaincy staff did still provide bedside spiritual support (Swift, 2020; Theos, 2021), much of it had to be offered by clinicians, nurses and other healthcare professionals working in ICUs.

Our review did not find any mention of an overarching, national or regional, strategy for the provision of spiritual support by the NHS in response to a health emergency. The only initiative around disaster chaplaincy training that we found looks promising (Guy's \& St Thomas' NHS Foundation Trust, 2020), but it is far from being a systematised and coordinated approach throughout the NHS. A national strategy would better prepare, equip, and guide specialised spiritual and pastoral care units in case of emergency and disaster, including highly contagious epidemics (Papadopoulos et al., 2020). Yet, it would also prepare all professionals across the system (Bornet et al., 2019), to cater for the spiritual support needs of patients, relatives, and themselves, in a time of severe spiritual suffering, and ethical challenges, around difficult treatment choices (Wakam et al., 2020). In fact, despite the increasingly recognised and inclusive role of chaplains within NHS England (Macdonald, 2019; Swift et al., 2015), frontline nurses continue to be key providers of spiritual support in emergency situations. According to Carey and Cohen (2015), in 2002, the WHO issued the Pastoral Intervention Codings (PICs) to record and account for the religious, pastoral and/or spiritual interventions of chaplains and volunteers providing care to patients. However, the same authors recommend that these codings should be further developed and 
promoted by the WHO in order to be viewed as accurate records of religious, pastoral and spiritual interventions. Our research did not specifically search for, or explore the use of the WHO-PICs, although it would have been interesting to discover whether and how the PICs were used during the extreme and hugely different conditions which persisted during the first peak of the COVID-19 pandemic. Additionally, our review found that there was very little discussion about patients' own perspective in order to guide the provision of spiritual support in the future. Nurses are not the only ones to be best placed to inform strategies and training (Veenema et al., 2016), as users' involvement is also crucial in healthcare policy making (Immonen, 2020; Pitts, 2020).

Another key finding revolves around the notion of virtual and remote spiritual support. Our searches have yielded several instances of 'words', statements, generic guidelines, on-line resources, in addition to symbolic initiatives (such as drawing rainbows and clapping hands to the NHS, which we did not included in this study), rather than 'actions' on behalf of spiritual support providers. While this is all positive and understandable given the necessary social distance, at the same time it raises questions around the effectiveness of these new forms of spiritual support and the changes in "being there" on behalf of pastoral and spiritual care teams (Swift, 2020). Remote spiritual support ultimately implies two evident, interlinked implications-digitally supported self-spiritual support and the lack of physical presence-from which several observations could be unrolled. First, more insights are needed around how patients in ICUs, who mostly needed EoL spiritual support, could access virtual spiritual support via the use of digital technological devices. Secondly, in relation to relatives, it appears that two keywords could well encapsulate their spiritual experience: solitude and intention (Cockell, 2020). Congregational rituals had to be suspended, and relatives were in quarantine and self-isolating; hence, celebrations and commemorations had to occur virtually and individually from home, including funerals and requested masses. For non-religious relatives, other actions revolved around the intention to establish closeness in distance, such as lighting a candle or incense, meditating, playing some music, displaying a photo of your loved one. All these practices call for a reflection around the effectiveness of rituals and the changes in religion/ religiosity (Baker et al., 2020), which traditionally entail the presence of a collective (Durkheim, 2008), and of the quality of the spiritual support offered, which pivots around dimensions pertaining to an interpersonal encounter (i.e. presence, being there, deep listening, compassion, hope, encouragement, connection, love, and talking together about higher meanings). There is no doubt that digital technologies have proven their usefulness during the COVID-19 outbreak (Ting et al., 2020). Studies are yielding promising results and found that people experience some comfort in giving/receiving virtual spiritual support. However, better understanding is needed to explore and improve new accepted conceptions and practices around spiritual support provision that the current pandemic has started unlocking (Betz et al., 2019; Drummond \& Carey, 2020; Ribeiro et al., 2020; Swift, 2020), including the virtualisation and modification of spiritual support, such as the key aspect of "being there", and new ways of "dying well" and providing holistic care in our fast evolving contemporary society. 


\section{Limitations}

This study presents limitations characterising the scoping review approach, such as no formal evaluation of studies' quality or risk of bias assessment, sizable number of studies included, need for multiple strategies, hand search and purposive sampling, overview results (Sucharew \& Macaluso, 2019). Additionally, the research utilised the internet as both a tool and object of research inquiry. Organisations with no presence on the Web could not be included. Furthermore, organisational websites may not have accurately represented or provided information around their spiritual support services, while instead having some provision in place. Finally, while our multi-strategy search aimed to be comprehensive, our findings are necessarily cross-sectional and subject to fast changing and updating, due to the fleeting nature of the Web (Devan et al., 2019).

\section{Conclusion and Implications}

COVID-19 pandemic has highlighted the crucial importance of spiritual support within the framework of holistic care, as a therapeutic healing tool for the bodymind-soul of the sick and dying, which helps reduce suffering especially in ICUs and EoL care. At the same time, this health emergency has unmasked the urgent need for centralised strategies to prepare healthcare systems and professionals in relation to spiritual support provision, both routinely, but mostly during health disasters and emergencies. Finally, further research will have to explore the innovative practices opened up by this coronavirus disease in terms of spiritual support provision. In particular, the role of digital technologies is promising, in avoiding a reduction in quantity and quality of spiritual support, while maintaining safety and ensuring spiritual support needs of all are better met.

Author's Contribution IP had the original concept for this study; RL, SW, PEL, and CK performed the search of the online evidence sources. RL drafted this article, and all authors critically revised and approved it.

Funding No funding was received to assist with the preparation of this manuscript.

Data Availability Full details of included data sources can be found in the study report (https://doi.org/10. 13140/RG.2.2.10785.02409). Further material (e.g. protocol and data extraction forms) can be requested from the corresponding author (IP).

\section{Compliance with Ethical Standards}

Conflict of interest All authors certify that they have no affiliations with or involvement in any organization or entity with any financial interest or non-financial interest in the subject matter or materials discussed in this manuscript. 
Ethics Approval This is a review study scoping information freely available in the public domain, with no involvement of human participants. Following Middlesex Ethics Committee guidelines, no ethical approval was required.

\section{References}

Achora, S., \& Kamanyire, J. K. (2016). Disaster preparedness. Sultan Qaboos University Medical Journal, 16(1), e15-e19. https://doi.org/10.18295/squmj.2016.16.01.004

Arksey, H., \& O'Malley, L. (2005). Scoping studies: Towards a methodological framework. International Journal of Social Research Methodology. https://doi.org/10.1080/1364557032000119616

Baker, J. O., Martí, G., Braunstein, R., Whitehead, A. L., \& Yukich, G. (2020). Religion in the age of social distancing: How COVID-19 presents new directions for research. Sociology of Religion, 81(4), 357-370. https://doi.org/10.1093/socrel/sraa039

Balboni, M. J., Sullivan, A., Enzinger, A. C., Epstein-Peterson, Z. D., Tseng, Y. D., Mitchell, C., Niska, J., Zollfrank, A., VanderWeele, T. J., \& Balboni, T. A. (2014). Nurse and physician barriers to spiritual care provision at the end of life. Journal of Pain and Symptom Management, 48(3), 400-410. https://doi.org/10.1016/j.jpainsymman.2013.09.020

Best, M., Leget, C., Goodhead, A., \& Paal, P. (2020). An EAPC white paper on multi-disciplinary education for spiritual care in palliative care. BMC Palliative Care, 19(1), 9. https://doi.org/10.1186/ s12904-019-0508-4

Betz, J., Szczesniak, R., Lewis, K., Pestian, T., Bennethum, A. S., McBride, J., \& Grossoehme, D. H. (2019). Feasibility and acceptability of a telephone-based chaplaincy intervention to decrease parental spiritual struggle. Journal of Religion and Health, 58(6), 2065-2085. https://doi.org/10.1007/ s10943-019-00921-8

Bland, A. M. (2020). Existential givens in the COVID-19 crisis. Journal of Humanistic Psychology, 60(5), 710-724. https://doi.org/10.1177/0022167820940186

Blustein, D. L., \& Guarino, P. A. (2020). Work and unemployment in the time of COVID-19: The existential experience of loss and fear. Journal of Humanistic Psychology, 60(5), 702-709. https://doi. org/10.1177/0022167820934229

Bornet, M.-A., Edelmann, N., Rochat, E., Cornuz, J., Poncin, E., \& Monod, S. (2019). Spiritual care is stagnating in general practice: The need to move towards an embedded model. The British Journal of General Practice: The Journal of the Royal College of General Practitioners, 69(678), 40-41. https://doi.org/10.3399/bjgp19X700613

Byrne, M. J., \& Nuzum, D. R. (2020). Pastoral closeness in physical distancing: The use of technology in pastoral ministry during COVID-19. Health and Social Care Chaplaincy, 8(2), 206-217. https:// journals.equinoxpub.com/HSCC/article/viewArticle/41625.

Carey, L. B., \& Cohen, J. (2015). The utility of the WHO ICD-10-AM pastoral intervention codings within religious, pastoral and spiritual care research. Journal of Religion and Health, 54(5), 17721787. https://doi.org/10.1007/s10943-014-9938-8

Carey, L. B., \& Gleeson, B. (2017). Spiritual-care intervention codings-Summary table. Palliative Care Unit and Health Information Management, Department of Public Health, La Trobe University.

Chapman, K., \& Arbon, P. (2008). Are nurses ready?: Disaster preparedness in the acute setting. Australasian Emergency Nursing Journal, 11(3), 135-144. https://doi.org/10.1016/j.aenj.2008.04.002

Chen, J., Lin, Y., Yan, J., Wu, Y., \& Hu, R. (2018). The effects of spiritual care on quality of life and spiritual well-being among patients with terminal illness: A systematic review. Palliative Medicine, 32(7), 1167-1179. https://doi.org/10.1177/0269216318772267

Cockell, N. (2020). COVID-19 and grief: A Chaplain's reflection on the experience of supporting bereaved parents and widows in lockdown. Health and Social Care Chaplaincy, 8(2), 251-264

Denzin, N. K., \& Lincoln, Y. S. (Eds.). (2017). The SAGE Handbook of Qualitative Research. (5th ed.). SAGE Publications.

Devan, H., Perry, M. A., van Hattem, A., Thurlow, G., Shepherd, S., Muchemwa, C., \& Grainger, R. (2019). Do pain management websites foster self-management support for people with persistent pain? A scoping review. Patient Education and Counseling, 102(9), 1590-1601. https://doi.org/ 10.1016/j.pec.2019.04.009 
Dezorzi, L. W., Raymundo, M. M., Goldim, J. R., \& de Oliveira, C. A. V. (2019). Spirituality in the continuing education of healthcare professionals: An approach to palliative care. Palliative and Supportive Care, 17(6), 662-667. https://doi.org/10.1017/S1478951519000117

Drummond, D. A., \& Carey, L. B. (2020). Chaplaincy and spiritual care response to COVID-19: An Australian case study-The McKellar centre. Health and Social Care Chaplaincy, 8(2), 165-179

Durkheim, É. (2008). The elementary forms of religious life (M. S. Cladis, Ed.; C. Cosman, Trans.). OUP Oxford.

Ebenau, A., Groot, M., Visser, A., van Laarhoven, H. W. M., van Leeuwen, R., \& Garssen, B. (2020). Spiritual care by nurses in curative oncology: A mixed-method study on patients' perspectives and experiences. Scandinavian Journal of Caring Sciences, 34(1), 96-107. https://doi.org/10. $1111 /$ scs. 12710

Ferrell, B. R., Handzo, G., Picchi, T., Puchalski, C., \& Rosa, W. E. (2020). The urgency of spiritual care: COVID-19 and the critical need for whole-person palliation. Journal of Pain and Symptom Management, 60(3), e7-e11. https://doi.org/10.1016/j.jpainsymman.2020.06.034

Gallison, B. S., Xu, Y., Jurgens, C. Y., \& Boyle, S. M. (2013). Acute care nurses' spiritual care practices. Journal of Holistic Nursing, 31(2), 95-103. https://doi.org/10.1177/0898010112464121

Ghorbani, M., Mohammadi, E., Aghabozorgi, R., \& Ramezani, M. (2020). Spiritual care interventions in nursing: An integrative literature review. Supportive Care in Cancer. https://doi.org/10.1007/ s00520-020-05747-9

Gijsberts, M.-J.H.E., Liefbroer, A. I., Otten, R., \& Olsman, E. (2019). Spiritual care in palliative care: A systematic review of the recent European literature. Medical Sciences (Basel, Switzerland), 7(2), 25. https://doi.org/10.3390/medsci7020025

Guy's and St Thomas' NHS Foundation Trust. (2020). Spiritual health care (chaplaincy) (UK). https://www.guysandstthomas.nhs.uk/Home.aspx

Heidari, M., Yoosefee, S., \& Heidari, A. (2020). COVID-19 pandemic and the necessity of spiritual care. Iranian Journal of Psychiatry, 15(3), 262-263. https://doi.org/10.18502/ijps.v15i3.3823

Ho, J. Q., Nguyen, C. D., Lopes, R., Ezeji-Okoye, S. C., \& Kuschner, W. G. (2018). Spiritual care in the intensive care unit: A narrative review. Journal of Intensive Care Medicine, 33(5), 279-287. https://doi.org/10.1177/0885066617712677

Hu, Y., Jiao, M., \& Li, F. (2019). Effectiveness of spiritual care training to enhance spiritual health and spiritual care competency among oncology nurses. BMC Palliative Care, 18(1), 104. https:// doi.org/10.1186/s12904-019-0489-3

Immonen, K. (2020). The views of patients and the public should be included in policy responses to covid-19. BMJ Opinion. https://blogs.bmj.com/bmj/2020/03/30/the-views-of-patients-and-thepublic-should-be-included-in-policy-responses-to-covid-19/.

International Council of Nurses, \& World Health Organization. (2011). ICN framework of disaster nursing competencies. ICN and WHO.

International Federation of Red Cross \& Red Crescent Societies. (2018). World disasters report 2018: Leaving no one behind. International Federation of Red Cross and Red Crescent Societies.

ISDR. (2007). Hyogo framework for action 2005-2015: Building the resilience of nations and communities to disasters. United Nations International Strategy for Disaster Reduction. https://www. coe.int/t/dg4/majorhazards/ressources/Apcat2005/APCAT-2005-25-Hyogo-frameworkISDR.pdf.

Johns Hopkins Coronavirus Resource Center. (2020). Maps\&Trends-Mortality analyses. Johns Hopkins Coronavirus Resource Center. https://coronavirus.jhu.edu/data/mortality

Levac, D., Colquhoun, H., \& O’Brien, K. K. (2010). Scoping studies: Advancing the methodology. Implementation Science, 5(1), 69

Macdonald, G. W. (2019). Spiritual care is stagnating in general practice. British Journal of General Practice, 69(679), 65-65. https://doi.org/10.3399/bjgp19X700937

Magnaye, B., Muñoz, M. S., Muñoz, M. A., Muñoz, R. G., \& Muro, J. H. (2011). The role, preparedness, and management of nurses during disasters. International Scientific Research Journal, 4 , 26

McBrien, B. (2010). Nurses' provision of spiritual care in the emergency setting-An Irish perspective. International Emergency Nursing, 18(3), 119-126. https://doi.org/10.1016/j.ienj.2009.09. 004

Nelson-Becker, H., \& Victor, C. (2020). Dying alone and lonely dying: Media discourse and pandemic conditions. Journal of Aging Studies, 55, 100878. https://doi.org/10.1016/j.jaging.2020.100878 
NHS England. (2017). NHS England emergency preparedness, resilience and response incident response plan (National). NHS England. https://www.england.nhs.uk/wp-content/uploads/2017/07/NHSengland-incident-response-plan-v3-0.pdf.

Paal, P., Helo, Y., \& Frick, E. (2015). Spiritual care training provided to healthcare professionals: a systematic review. The Journal of Pastoral Care and Counseling: JPCC, 69(1), 19-30. https://doi.org/ $10.1177 / 1542305015572955$

Papadopoulos, I. (1999). Spirituality and holistic caring: An exploration of the literature. Implicit Religion, 2(2), 101-107. https://doi.org/10.1558/imre.v2i2.101.

Papadopoulos, I. (2018). Culturally competent compassion. London: Routledge.

Papadopoulos, I., \& Copp, G. (2005). Nurse lecturers' perception and teaching of spirituality. Implicit Religion, 8(1), 22-39.

Papadopoulos, I., Lazzarino, R., Wright, S., Poppy, E. L., \& Koulouglioti, C. (2020). Spiritual support for hospitalised COVID-19 patients during March to May 2020. Research Centre for Transcultural Studies in Health, Middlesex University. https://cultureandcompassion.com/Spirituality/.

Peters, M., Godfrey, C., McInerney, P., Munn, Z., Trico, A., \& Khalil, H. (2020). Chapter 11: Scoping reviews. In E. Aromataris \& Z. Munn (Eds.), JBI manual for evidence synthesis.JBI. https://doi.org/ 10.46658/JBIMES-20-12

Piscitello, G. M., \& Martin, S. (2020). Spirituality, religion, and medicine education for internal medicine residents. The American Journal of Hospice \& Palliative Care, 37(4), 272-277. https://doi.org/10. $1177 / 1049909119872752$

Pitts, P. J. (2020). Our most powerful weapon to fight COVID-19: Patient Involvement. The Patient Patient-Centered Outcomes Research, 13(3), 255-255. https://doi.org/10.1007/s40271-020-00421-y

Ramezani, M., Ahmadi, F., Mohammadi, E., \& Kazemnejad, A. (2014). Spiritual care in nursing: A concept analysis. International Nursing Review, 61(2), 211-219. https://doi.org/10.1111/inr.12099

Ribeiro, M. R. C., Damiano, R. F., Marujo, R., Nasri, F., \& Lucchetti, G. (2020). The role of spirituality in the COVID-19 pandemic: A spiritual hotline project. Journal of Public Health. https://doi.org/10. 1093/pubmed/fdaa120

Roman, N. V., Mthembu, T. G., \& Hoosen, M. (2020). Spiritual care-'A deeper immunity'-A response to Covid-19 pandemic. African Journal of Primary Health Care \& Family Medicine. https://doi.org/ $10.4102 /$ phcfm.v12i1.2456

Royal College of Nursing. (2011). Spirituality in nursing care: A pocket guide (003 887). Royal College of Nursing. http://www.elament.org.uk/media/1205/spirituality_in_nursing_care-_rcn_pocket_ guide.pdf.

Rushton, L. (2014). What are the barriers to spiritual care in a hospital setting? British Journal of Nursing, 23(7), 370-374. https://doi.org/10.12968/bjon.2014.23.7.370

Schultz, C. H., Koenig, K. L., Whiteside, M., Murray, R., \& National Standardized All-Hazard Disaster Core Competencies Task Force. (2012). Development of national standardized all-hazard disaster core competencies for acute care physicians, nurses, and EMS professionals. Annals of Emergency Medicine, 59(3), 196-208.e1. https://doi.org/10.1016/j.annemergmed.2011.09.003

Seale, C. (2004). Media constructions of dying alone: A form of 'bad death.' Social Science and Medicine, 58(5), 967-974. https://doi.org/10.1016/j.socscimed.2003.10.038

Sellwood, C. (2017). operating framework for managing the response to pandemic influenza. NHS England. https://www.england.nhs.uk/wp-content/uploads/2017/12/nhs-england-pandmic-influenzaoperating-framework-v2.pdf.

Sinclair, S., Pereira, J., \& Raffin, S. (2006). A thematic review of the spirituality literature within palliative care. Journal of Palliative Medicine, 9(2), 464-479. https://doi.org/10.1089/jpm.2006.9.464

Sucharew, H., \& Macaluso, M. (2019). Methods for research evidence synthesis: The scoping review approach. Journal of Hospital Medicine. https://doi.org/10.12788/jhm.3248

Swift, C. (2020). Being there, virtually being there, being absent: Chaplaincy in social care during the COVID-19 pandemic. Health and Social Care Chaplaincy, 8(2), 154-164. https://doi.org/10.1558/ hscc. 41870

Swift, C., Chaplaincy Leaders Forum, \& National Equality and Health Inequalities Team. (2015). NHS Chaplaincy guidelines 2015 promoting excellence in pastoral, spiritual \& religious care. NHS England. https://www.england.nhs.uk/wp-content/uploads/2015/03/nhs-chaplaincy-guidelines-2015.pdf.

The Guardian. (2020). 'Chaos and panic': Lancet editor says NHS was left unprepared for Covid-19. The Guardian. https://www.theguardian.com/world/2020/mar/28/chaos-and-panic-lancet-editor-saysnhs-was-left-unprepared-for-covid-19. 
Theos. (2021). Care under Covid-19: Providing spiritual and pastoral support at a distance. Theos Think Tank. https://www.theosthinktank.co.uk/events/2021/02/03/care-in-the-covid-crisis-what-does-spiri tual-and-pastoral-support-look-like-at-a-distance.

Ting, D. S. W., Carin, L., Dzau, V., \& Wong, T. Y. (2020). Digital technology and COVID-19. Nature Medicine, 26(4), 459-461. https://doi.org/10.1038/s41591-020-0824-5

Turner, N., \& Caswell, G. (2020). Moral ambiguity in media reports of dying alone. Mortality, 25(3), 266-281. https://doi.org/10.1080/13576275.2019.1657388

van Gennep, A. (2019). The rites of passage (D. I. Kertzer, Ed.; M. B. Vizedom \& G. L. Caffee, Trans.; 2nd ed.). University of Chicago Press.

Veenema, T. G., Griffin, A., Gable, A. R., MacIntyre, L., Simons, R. N., Couig, M. P., Walsh, J. J., Lavin, R. P., Dobalian, A., \& Larson, E. (2016). Nurses as leaders in disaster preparedness and responseA call to action. Journal of Nursing Scholarship: An Official Publication of Sigma Theta Tau International Honor Society of Nursing, 48(2), 187-200. https://doi.org/10.1111/jnu.12198

Wakam, G. K., Montgomery, J. R., Biesterveld, B. E., \& Brown, C. S. (2020). Not dying alone-Modern compassionate care in the Covid-19 pandemic. New England Journal of Medicine, 382(24), e88. https://doi.org/10.1056/NEJMp2007781

Walton, M. N. (2012). Assessing the construction of spirituality: Conceptualizing spirituality in health care settings. Journal of Pastoral Care and Counseling, 66(3), 1-16. https://doi.org/10.1177/15423 0501206600307

WHO. (2017). ICD-10-AM: International statistical classification of diseases and related health problems. (10th ed.). World Health Organization.

WHO. (2019). Health Emergency and Disaster Risk Management Framework. World Health Organization. https://apps.who.int/iris/bitstream/handle/10665/326106/9789241516181-eng.pdf.

WHO. (2020). Practical considerations and recommendations for religious leaders and faith-based communities in the context of COVID-19. WHO.

Publisher's Note Springer Nature remains neutral with regard to jurisdictional claims in published maps and institutional affiliations. 